\title{
APOLICES DE RENDA PERPETUA
}

\author{
"Il faut arrêter le flot toujours mon- \\ tant des dépenses et des dettes publi- \\ ques. Il 'faut aussi s'éfforcer de dimi- \\ nuer le capital des dettes publiques, en \\ le remboursant. \\ prévoyance." \\ ... C'est un devoir de patriotique, \\ (Leroy Beaulieu - Précis d'Écono- \\ mie, p. 398).
}

Discute-se no Congresso Paulista, o projecto n. ${ }^{\circ}$ 18, autorizando o Governo a emittir apolices de renda perpetua, e, pelo discurso do illustre deputado Dr. Plinio de Godoy, vê-se que não se trata de apolices irredimiveis ou perpetuas, no sentido que lhe dá a Sciencia das Finanças, isto é, de "apolices sem prazo para o resgate", ou para a amortização, "detto volgarmente rendita perpetua, per cui lo Stato é tenuto soltanto al pagamento degl'interessi, rimanendo per lui facoltativo l'ammortamento o il rimborso" (Ricca Salerno, "Scienza delle Finanze", paragrapho 116), mas de titulos inconversiveis, irresgataveis "eternamente".

O modo por que entendeu o Dr. Plinio de Godoy o projecto é autorizado ou justificado pelo parecer das Com. missões de Justiça e Fazenda, quando diz que se trata de um "ensaio, de uma idéa nova" (Textual). As observações feitas pelo laborioso deputado a que nos referimos foram julgadas de tal valor, que um dos membros da Commissão requereu fosse o projecto de novo estudado por ella, em vista dos valiosos argumentos produzidos pelo talentoso deputado contrario á idéa.

Basta ter presente o que seja o Estado, para vêr que inacceitavel é o plano de renda perpetua em favor de certas familias, e não póde haver, em tal caso, propriamente individuos, mas geraçóes, como titulares desse direito de credito contra o Estado. 
Sabido é que o Estado se modifica profundamente, e modificam-se suas necessidades, sendo este motivo primordial por que uma geração não póde ligar as gerações futuras, estabelecendo institutos immutaveis.

Desenvolverei este asserto, admittindo que se trata no projecto em questão de rendas realmente perpetuas, no sentido vulgar do termo.

Os civilistas, e entre elles "Windscheid", dão por incontestavel que uma geração não póde fazer uma lei, declarando que ás futuras gerações não será dado abrogal-a. Si tal acontecesse, dizem certos espiritos agudos, os posteros começariam pela derogação da parte da lei prohibindo que elles a modificassem, e em seguida modificariam a propria instituição.

$\mathrm{Na}$ Sciencia das Finanças, e mais propriamente em referencia ao assumpto que occupa agora minha attenção, ensinam os mestres que ao Estado é sempre licito pagar por anticipação.

Diz o saudoso Dr. "Veiga Filho": — "Quanto ao resgate, a despeito da conveniencia de ser sempre anteriormente convencionado entre o Estado e mutuarios, todavia pódem estes ser obrigados ao reembolso, antes de expirado o prazo estipulado. $\mathrm{O}$ direito de um Estado resgatar um emprestimo provém do facto de se tratar de um negocio que affecta directamente o interesse publico e a personalidade do Estado, em seu credito, perante os demais Estados. Exige, portanto, a applicáção de preceitos especiaes, tanto mais porque não se trata de um devedor commum. Em taes emprestimos, o prazo é estabelecido em favor do devedor, maximé quando os titulos da transacção fraccionando o capital, são negociaveis "ad libitum" do mutuante, como effectivamente o são nas Bolsas". (Sciencia das Finanças, paragrapho 125).

No mesmo sentido do Dr. "Veiga Filho", e suffragando sua lição, temos "Cossa", quando diz: "Che anzi sembra repugnante che un debitore possa obbligarsi a non 
estinguere mai il suo debito". (Sc. delle Finanze, C. 4, paragrapho 2). Em quaesquer circumstancias, quer se trate de emprestimo com prazo fixo, quer sem prazo, póde sempre o Estado se desobrigar.

Ainda ha uma consideração contra o projecto, e é a seguinte: si ao Estado é dado o poder de desapropriar, claro, evidente mesmo é que, si ficasse obrigado perpetuamente, teria o direito de desapropriar o seu credor do direito de credito nascido do projecto $\mathrm{n}^{\circ} 18$ e do emprestimo feito por força de tal projecto convertido em lei.

Fóra este recurso de desapropriação, teria ainda o Estado o da amortização, fazendo "achetêr à la Bourse au cours du jour un certain nombre de titres... et à les détruire ensuite en les frappant d'un timbre d'annullation". ("Gide", Éc. Polit., pag. 631). Assim, os titulos de "renda perpetua", ou "eterna" (expressão autorizada em caso analogo por "Leroy Beaulieu", como se vê no sẹu Tratado de Sc. das Finanças, v. 2, pags. 210 e 223), seriam de facto resgataveis pelo Estado.

Como se vê, o projecto n. $^{\circ} 18$ vem alterar a unidade do systema juridico que rege as relações creditorias entre a Estado e seus credores.

Mas passarei da região dos principios á realidade da vida, e mostrarei que, quando fosse possivel este genero de emprestimos, seria entretanto incopnvenientissimo para o Estado de S. Paulo.

Em primeiro lugar, é bom ter presente que uma das idéas mais afagadas actualmente pelos mestres em Sciencia de Finanças é a de nada deverem os Estados, senão excepcionalmente, e alguns extremados só admittem emprestimos para guerras externas ou internas ("Coquelin e Guillaumin", Dictionnaire de L'Economie Politique, vers. "Crédit Public." p. 654, artigo de "Gustavo de Puynode").

Não irei até lá, pois entendo que é algum tanto difficil limitar as funcções do Estado, e acceito a formula. quanto a este assumpto, defendida por "Leroy. Beaulieu", 
"Romagnosi" e outros, conforme explicarei em artigo posterior.

Si multiplas são as funcções do Estado, além de defesa interna e externa, é de concluir que, quando seu desempenho depende de meios pecuniarios, em casos extraordinarios, deve elle recorrer a meios tambem extraordinarios, quando insufficiente for o imposto que acode ás necessidades ordinarias. Comquanto me pareça que o Estado póde tomar dinheiro de emprestimo, fóra dos casos de guerra e revolução, como tratarei de provar em outro artigo, devo lembrar que a regra é não ter divida, contentando-se com os serviços que póde fazer por meio dos recursos ordinarios dados pelos impostos. Apresentarei, tirádo da historia da nossa vida financeira, um exemplo de tentativa de libertação da nossa Patria, de todas as suas dividas por apolices. Refiro-me á operação do "C. Belizario," em 1886.

Segundo diz o Dr. "Veiga Filho", fundado no Relatorio da Fazenda de 1897, p. 57, si se tivesse applicado a resgate das apolices o producto da economia realizada pela feliz operação do grande estadista, "em 1924, não haveria mais no orçamento o encargo que lhe trazem as apolices da divida publica" (Obra cit., pg. 438). Pelo exposto, torna-se patente que é perfeitamente possivel, mesmo natural, que queiram as futuras geraçóes, sob a direcção de outro "C. ${ }^{\circ}$ Belizario", realizar uma nova operação liberatoria das responsabilidades economicas da Patria, e ficariam embaraçadas si houvesse sido transformado em lei o projecto n. ${ }^{\circ} 18$.

Ha ainda uma outra consideração contra o projecto. Si tivermos presente uma successão sem limites no tempo, chegaremos, ao fim de um certo numero de gerações, a - achar tão dividido o credito contra o Estado entre os herdeiros do primitivo credor pelas repetidas partilhas, que cada titular será credor por uma quantia ridicula, devendo o Estado occupar-se em pagar ninharias, facto cujas incon- 
venientes consequencias são de facil previsão: imaginemos o Estado a pagar a um individuo um real de juros!... Tentou-se defender o projecto, dizendo que era para tornar effectivo o vinculo instituido pelo Codigo Civil, que reproduziu os preceitos da lei n. ${ }^{\circ} 1839$ de 1907, e sustentou-se que taes titulos seriam intransferiveis. Ora, por mais que me esforce, não posso comprehender como "essas apolices de renda perpetua constituam uma garantia seria e efficaz ás doações e heranças vinculadas", como diz a Commissão, salvo si, no projecto, se houvesse posto (o que não succedeu) algum preceito prohibindo sua transferencia "inter vivos", o que seria uma razão para serem repellidas por qualquer capitalista, pois, como explica "Leroy Beaulieu", a acceitação que têm os emprestimos sem prazo, é filha da possibilidade que tem o credor de realizar "à chaque instant, son capital, s'il arrive qu'il en ait le besoin ou le désir", vendendo o titulo da Bolsa (Sc. das Finanças, v. 2, p. 208). Mas, dado que o projecto seja destinado a garantir os vinculos, o remedio seria forte de mais.

$\mathrm{O}$ instituto do vinculo, que encontrou grande opposição, e que provavelmente será, para a felicidade de nossa Patria, abolido dentro em pouco tempo, limitou a restrịcção da propriedade a uma geração. O projecto vae além, e indirectamente deroga o final do "art. 1723 do Codigo Civil", onde se limita a uma geração a inalienabilidade, quando diz a lei: "A qual não prejudicará a livre disposição testamentaria, e, na falta desta, a transferencia dos bens aos herdeiros legitimos, desembaraçados de qualquer onus.

Si o projecto $n^{\circ} 18$ se converter em lei, poderá qualquer avarento impedir que seus herdeiros transmittam aos outros, por testamento ou "ab intestato", os bens livres de quaesquer onus: temos assim uma lei estadual derogando preceito do Codigo Civil. Isto digo, fique bem 
claro, admittindo, que o projecto tenha a efficacia que lhe attribue a Commissão, que é de garantir os vinculos. Admittamos porém que o projecto fala de emprestimo perpetuo no sentido que lhe dão os mestres da Sciencia das Finanças: emprestimos que o Estado póde resgatar a qualquer tempo, sem ter o credor direito de exigir o resgate ou a amortização, mas sómente o juro. Ainda neste caso, com quanto não seja contrario o projecto aos principios que regem a materia, é comtudo inconveniente por deixar margem á imprevidencia dos governos.

Bem sei que os emprestimos sem prazo ou irredimiveis são os que constituem a regra nos Estados modernos (Salerno, paragrapho 107), mas devemos ter deante de nós que isto é razoavel em Estados antigos, e não nos da joven America, que deve dar maiores vantagens aos credores, e cujos governos são menos estaveis do que os da velha Europa, donde a necessidade de não crear no espirito do capitalista o temor de um abuso por parte de futuros administradores.

Aos Estados novos, ainda pouco conhecidos e dirigidos por governos temporarios, cumpre que, para terem bom typo e juros modicos nos emprestimos, estabeleçam um prazo certo de pagamento, por meio de resgate ou amortização. Não é momento opportuno para indagar qual o meio preferivel de pagamento, e sabem todos aquelles que não são inteiramente extranhos ás finanças, que muitos são os prucessos de extincção do debito publico. Eu preferiria, digo, entretanto, o sorteio em prazos prefixados, de modo a extinguir-se o debito dentro de um limitado e determinado numero de annos. Tudo isto digo no presupposto de que o Estado tem necessidade de dinheiro no momento actual, porque, si apenas quer converter seus titulos em outros, para ampliar o pessimo, antieconomico, antidemocratico, absurdo, antiquado e condemnado "instituto do vinculo", como se póde inferir da combinação do art. 1 do projecto com o art. 3, o melhor é nada fazer. 
Não deixarei a penna sem lembrar que analogo ao projecto $n .^{\circ} 18$, analysado neste meu artigo, ha um processo de emprestimo publico já experimentado, mas que não teve grande acceitação: é o das rendas vitalicias, ou por um certo numero de annos, que excedem á vida humana. (Leroy Beaulieu, obra cit., v. 2, pags. 212 e 223). O Estado recebe certo capital e paga uma annuidade (verdadeira pensão) durante uma vida ou durante 100 , ou 200 annos. Ao fim desse termo fica livre, independente do pagamento do capital.

Sem pretender vir dar lições aos mestres em assumptos economicos, tenho a dizer que julgo ter defendido as seguintes theses: não ha razão para se estabelecerem rendas perpetuas, no rigor grammatical do termo; quando fosse licito estabelecel-as, ellas constituiriam vinculos perpetuos contra o disposto no final do art. 1.723 do Codigo Civil Brasileiro; quando um Estado novo, como é o nosso, precisa de dinheiro, deve preferir o emprestimo a prazo fixo ao chamado em Sciencia de Finanças perpetuo, que é o que póde ser pago quando o Estado tiver meios e quizer, ainda que seja em geral adoptado pelos paizes antigos o systema de emprestimo para pagamento quando as condições economicas do paiz permittem.

Um conselho de maior importancia, e de que comtudo zombam quasi todos os Estados, segundo "Gide" (Economie, pag. 630), é o dado por "Jefferson". O honrado presidente norte-americano dizia que uma geração não tem direito de contrahir uma divida, a não ser para pagal-a durante sua vida, e não pelos seus descendentes; e fixava, por isto, o maximo do termo para amortizar-se um emprestimo publico, em 30 ou 40 annos.

Não se deve aceitar rigorosamente á letra este conselho: póde acontecer que as novas gerações venham a gozar dos beneficos effeitos de uma operação dessa natureza, e então é justo que concorram para sua solução. $\mathrm{Na}$ generalidade dos casos, porém, tem razão "Jefferson". 
Em artigo subsequente, occupar-me-ei dos casos em que são admissiveis os emprestimos, e da melhor fórma a dar-lhes, particularmente em relação ao pagamento. E' assumpto de grande interesse para a vida economica de um Estado.

S. Paulo, Outubro de 1916.

Braz de Sousa Arruda,

Docente da Faculdade. 